\title{
Treatment of Unstable Pelvic Ring Injuries
}

\author{
Weon-Yoo Kim, MD \\ Department of Orthopedic Surgery, Daejeon St. Mary's Hospital, \\ The Catholic University of Korea, Daejeon, Korea
}

Pelvic fractures are classified according to the stability of the pelvic ring. Unlike stable pelvic fractures, which heal without complications, unstable fractures may lead to pelvic ring deformities, which cause severe complications. An orthopedic surgeon must determine the stability of the pelvic ring by radiography and physical examination of the patient in order to ensure early, prompt treatment. This article includes anatomy of the pelvic ring, classification of pelvic ring injuries, its treatment algorithm, and corresponding cases involving unstable pelvic ring injury.

Key Words: Pelvis, Pelvic bones, Therapeutics, Clinical protocols, Review literature as topic

\section{INTRODUCTION}

Pelvic fractures are mainly divided into unstable fractures resulting in pelvic ring deformity, and stable fractures, which include pubic ramus, iliac wing and avulsion fractures ${ }^{1-6}$. Determining pelvic ring stability after a pelvic fracture is important, because stable pelvic fractures are usually managed successfully with conservative treatment and do not lead to complications ${ }^{7-111}$. On the other hand, according to the practice guidelines for managing unstable pelvic fractures, early prompt

Submitted: July 11, 2013 1st revision: October 2, 2013

2nd revision: November 27, 2013 3rd revision: December 11, 2013

4rd revision: January 6, 2014 5rd revision: January 27, 2014

6rd revision: February 1, 2014 7rd revision: March 24, 2014

Final acceptance: April 8, 2014

Address reprint request to

Weon-Yoo Kim, MD

Department of Orthopedic Surgery, Daejeon St. Mary's Hospital,

The Catholic University of Korea, 64 Daeheung-ro, Jung-gu,

Daejeon 301-723, Korea

TEL: +82-42-220-9530 FAX: +82-42-221-0429

E-mail: weonkimahotmail.com

This is an Open Access article distributed under the terms of the Creative Commons Attribution Non-Commercial License (http://creativecommons. org/licenses/by-nc/3.0) which permits unrestricted non-commercial use, distribution, and reproduction in any medium, provided the original work is properly cited. treatment is crucial in such cases because of potentially life-threatening injuries and a high prevalence of massive internal bleeding in the pelvis. Late treatment is associated with a high incidence of complications such as shortening of a lower extremity, pelvic obliquity, walking difficulty, pain when sitting down, disorders of urination, evacuation and sexual intercourse ${ }^{12-15}$.

\section{MAIN SUBJECTS}

\section{Anatomy and Biomechanics}

The pelvis is made up of three bones, two innominate bones and the sacrum; each innominate bone is composed of the ilium, pubis and ischium. Three ossification centers of ilium, pubis and ischium grow out radially and fuse at the acetabular triradiate cartilage at the age of 16 years. Two innominate bones and the sacrum are strongly interconnected by soft tissue structures. The stability of the pelvic ring is determined by the weight-bearing line passing through the sacroiliac joint and the femoral neck, so the main structures involved in hip stability are located posteriorly. The symphysis pubis serves as a strut to prevent anterior collapse of the pelvic ring during weight bearing.

The absence of this anterior strut, as in patients with 


\section{Hip \& Pelvis}

Hip Pelvis 26(2): 79-83, 2014

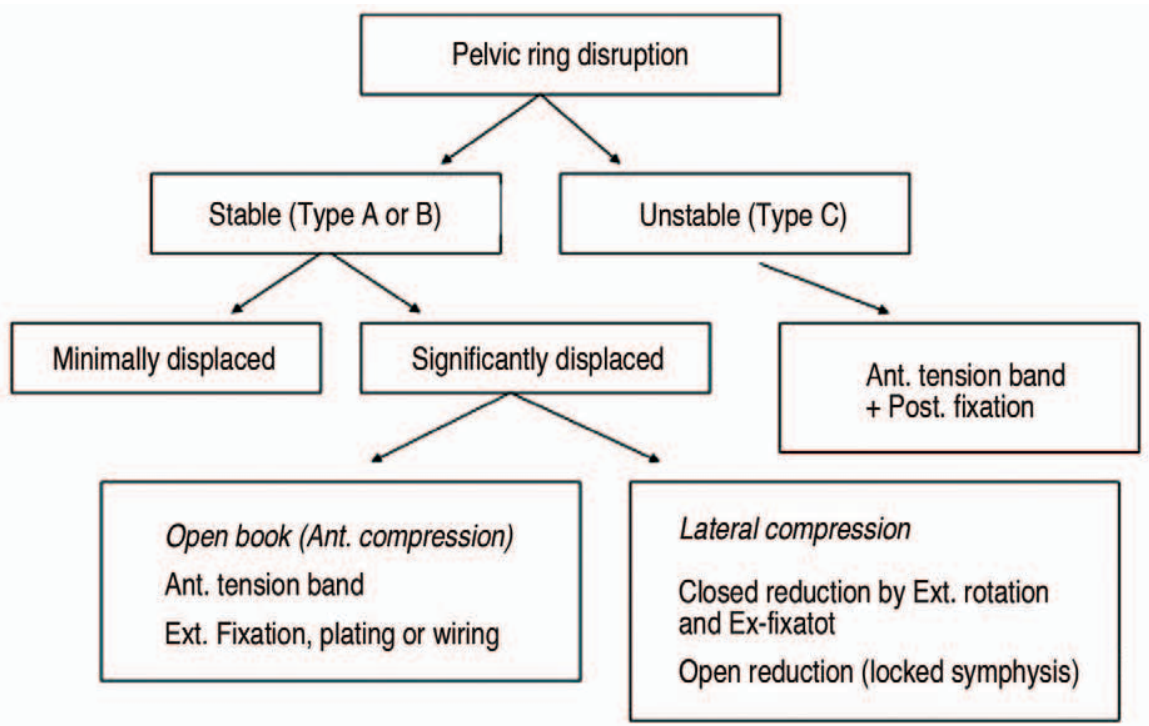

Ant.: anterior, Ext.: external.

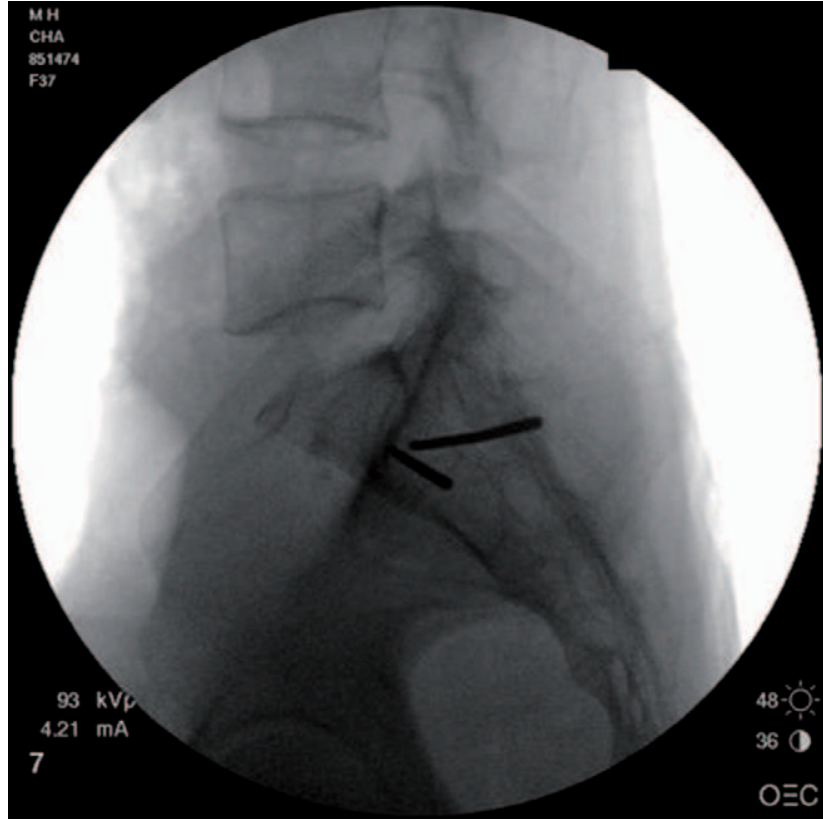

Fig. 1. Two guided pins behind the iliac cortical density.

congenital exotrophy of the bladder or trauma victims, only minimally affects the weight-bearing function. Sacroiliac ligaments stabilizing the sacroiliac joints that maintain posterior pelvic stability are classified into the interosseous sacroiliac ligament (the strongest ligament in the body), and anterior and posterior sacroiliac ligaments. The other major ligaments of the pelvis are the sacrotuberous, sacrospinous, iliolumbar, and lateral lumbosacral ligaments. The sacrotuberous and sacrospinous ligaments that make up the pelvic floor are also known as pelvic floor ligaments. The presence of an avulsion fracture associated with the rupture of ligaments connecting the bones of the pelvis is helpful for determining the stability of pelvic fractures. Pelvic fractures are divided into stable, partially stable (rotationally unstable, vertically stable) and completely unstable (vertically unstable) fractures ${ }^{10)}$. Stable fractures are characterized by the absence of ligament disruption in the pelvic ring, whereas no injury in the posterior ligament structures is observed in partially stable fractures. Completely unstable fractures are accompanied by the most severe forms of injury, such as a deformity resulting in an upward movement of the pelvic bones due to strong attraction of abdominal and lumbar muscles damaged by injuries in the pelvic floor ligaments and posterior ligament structures.

\section{Determination of Pelvic Stability and Fracture Classification}

Pelvic stability mainly depends on the stability of the posterior ligament structures, pelvic floor muscles, ligaments and fascia. Complete vertical instability is clinically or radiographically characterized by anterior or posterior displacement of the sacroiliac joints by more than $1 \mathrm{~cm}^{10)}$. The findings of a computed tomography (CT) scan are the best way to detect injuries in both sacroiliac joints. The Pennal ${ }^{6)}$ classification is widely used to discriminate the fracture patterns on the basis of the direction of forces exerted on the pelvis; 


\section{Hip \& Pelvis}

Weon-Yoo Kim. Treatment of Unstable Pelvic Ring Injuries

according to this classification, the types of pelvic injuries are: anterior posterior compression, lateral compression, and vertical shear injuries. The direction of forces exerted on the pelvis has different effects on injuries of the soft tissues and internal organs. For example, an anteroposterioror compression force results in the rupture of the internal organs, blood vessels, and nerves, whereas a lateral compression force generates direct penetrating injuries caused by fractured bony fragments. However, pelvic stability cannot be determined only on the basis of the fracture types classified according to the force direction. For this reason, the AO group has adopted the Tile ${ }^{10,11}$ classification of pelvic fractures, which is based on pelvic stability and the results of biomechanical analysis. This classification system is commonly used worldwide and is also known as the "universal classification". According to the Tile classification, fractures are divided into the following types: A, stable; B, partially stable (rotationally unstable, vertically stable); and $\mathrm{C}$, completely unstable (vertically unstable $)^{10)}$. Furthermore, the classification system of Young et al. ${ }^{16)}$, which uses the Pennal ${ }^{6}$ classification but also takes into account stability in addition to the deforming force, is often used to understand the mechanism of injury in regard to pelvic fractures.
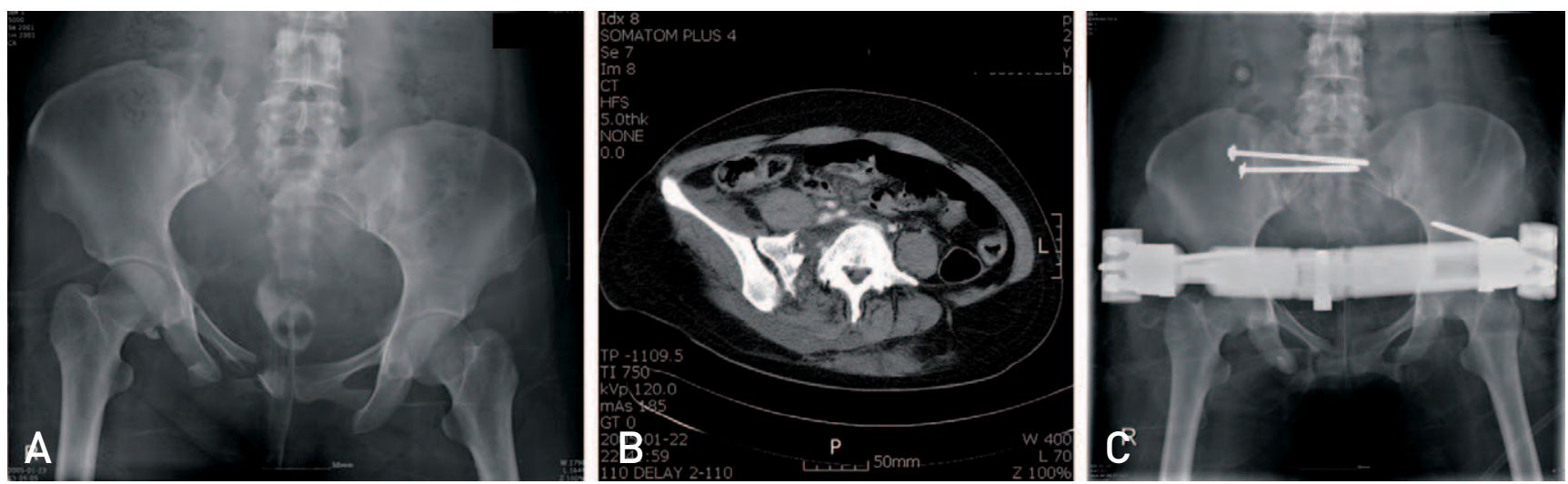

Fig. 2. Satisfactory reduction and early mobilization was performed with percutaneous iliosacral fixation and an anteroinferior external fixator.
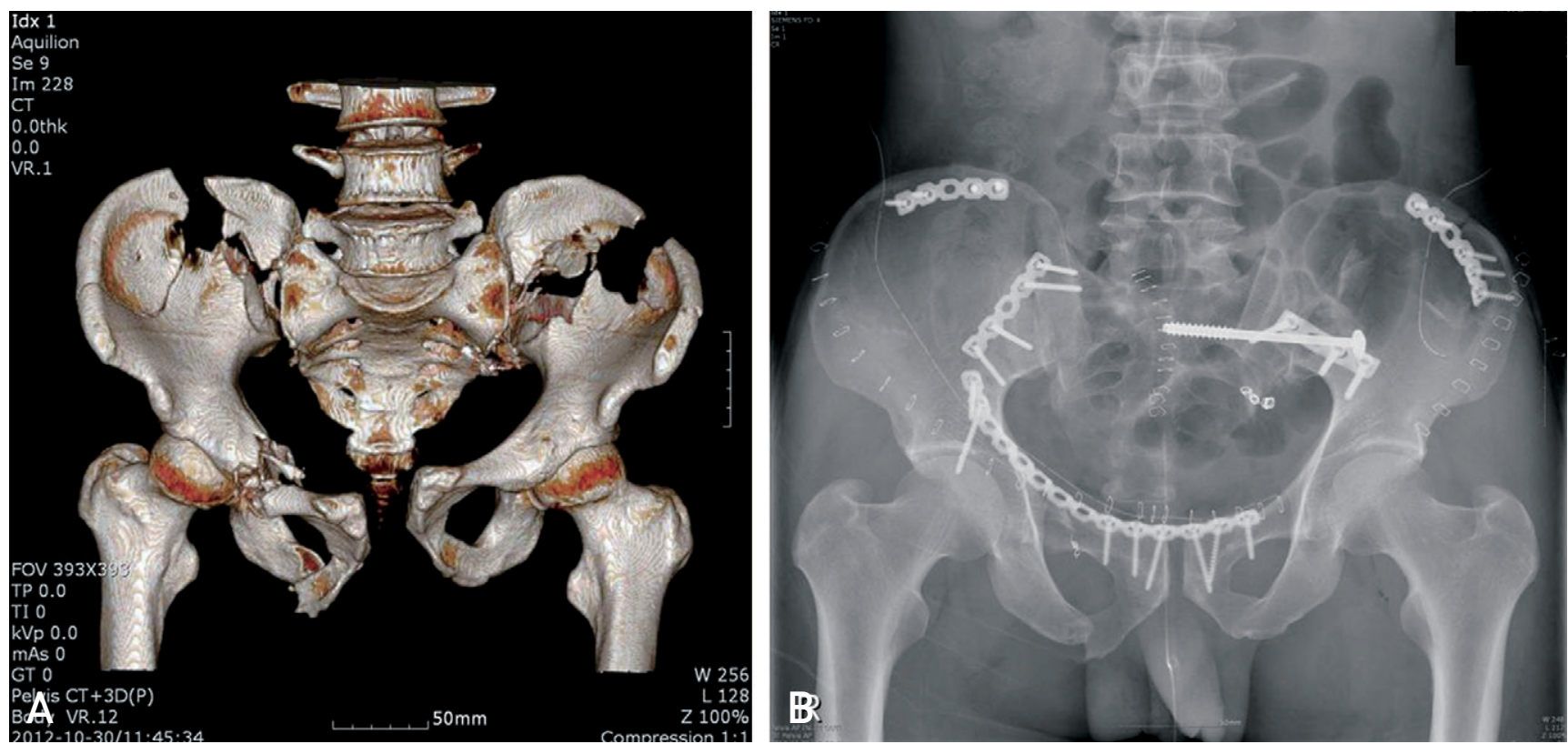

Fig. 3. A 3-dimensional computed tomography image (A) of a severely comminuted pelvic fracture and a postoperative radiograph $(\mathrm{B})$ showing open reduction and rigid internal fixation with plates and screws. 


\section{Hip \& Pelvis}

Hip Pelvis 26(2): 79-83, 2014

\section{Assessment and Management of Polytrauma Patients}

Open reduction, external fixation, and other methods are increasingly used based on the reported results of autopsy and radiographic findings for polytrauma patients. In a study by Bucholz ${ }^{17)}$, necropsy findings revealed that pelvic fractures were observed in 47 (37\%) out of 150 cases of fatal car accidents and vertical fractures were detected in 32 cases, indicating the significance of the pelvic bone injuries. Multiple-trauma patients should be examined and managed according to their injuries in the following order: A, airways; B, bleeding; C, central nervous system; D, digestive; and E, excretory. Pelvic fractures correspond to case B. In cases when blood pressure cannot be regulated despite hemostasis of external bleeding, surgical procedures are required when positive manifestation is observed in mini-laparotomy performed to identify abdominal bleeding. In cases of persistent bleeding or a negative response to laparotomy, hemostasis of pelvic hemorrhage is the most critical process in reducing pelvic dead space by conducting external fixation ${ }^{2,9}$. If blood pressure continues to drop, embolization needs to be performed in cases of arterial bleeding; bleeding sites in the pelvic cavity needs to be filled with surgical gauze in cases of venous bleeding during emergency angiography.

\section{Surgical Treatment of Pelvic Fractures}

Pelvic fracture surgery aims to prevent associated complications (including malunion and nonunion), provide early management (including improvement of systemic state and prevention of decubitus ulcers), and enable early ambulation by repairing injuries and displacement of the pelvic ring. Pelvic ring injuries are mainly characterized by diastasis of anterior structures and dislocation of posterior structures. Biomechanically, the anterior structures of the pelvic ring function as tension bands. They are repaired by performing internal fixation to fracture or diastasis at or near the pubic symphysis using fixators, plates, screws, cables or wires ${ }^{5}$. Subsequently, reduction and fixation of the posterior sacroiliac complex are the most important steps to ensure pelvic ring stability. Plates, screws, sacral bars or rods, or cannulated screws are inserted to improve fixation, which is insufficient with an anterior fixation. Although there are internal fixation methods through an anterior or posterior approach ${ }^{5,18}$, closed reduction and percutaneous screw fixation are the preferred techniques. Surgical procedures are generally conducted using a $\mathrm{C}$-arm image intensifier, but a navigation system or 2-dimensional and 3-dimensional $\mathrm{CT}$ guidance is used as well ${ }^{21)}$. External fixation can adequately control Tile type $\mathrm{B}$ injuries ${ }^{22)}$.
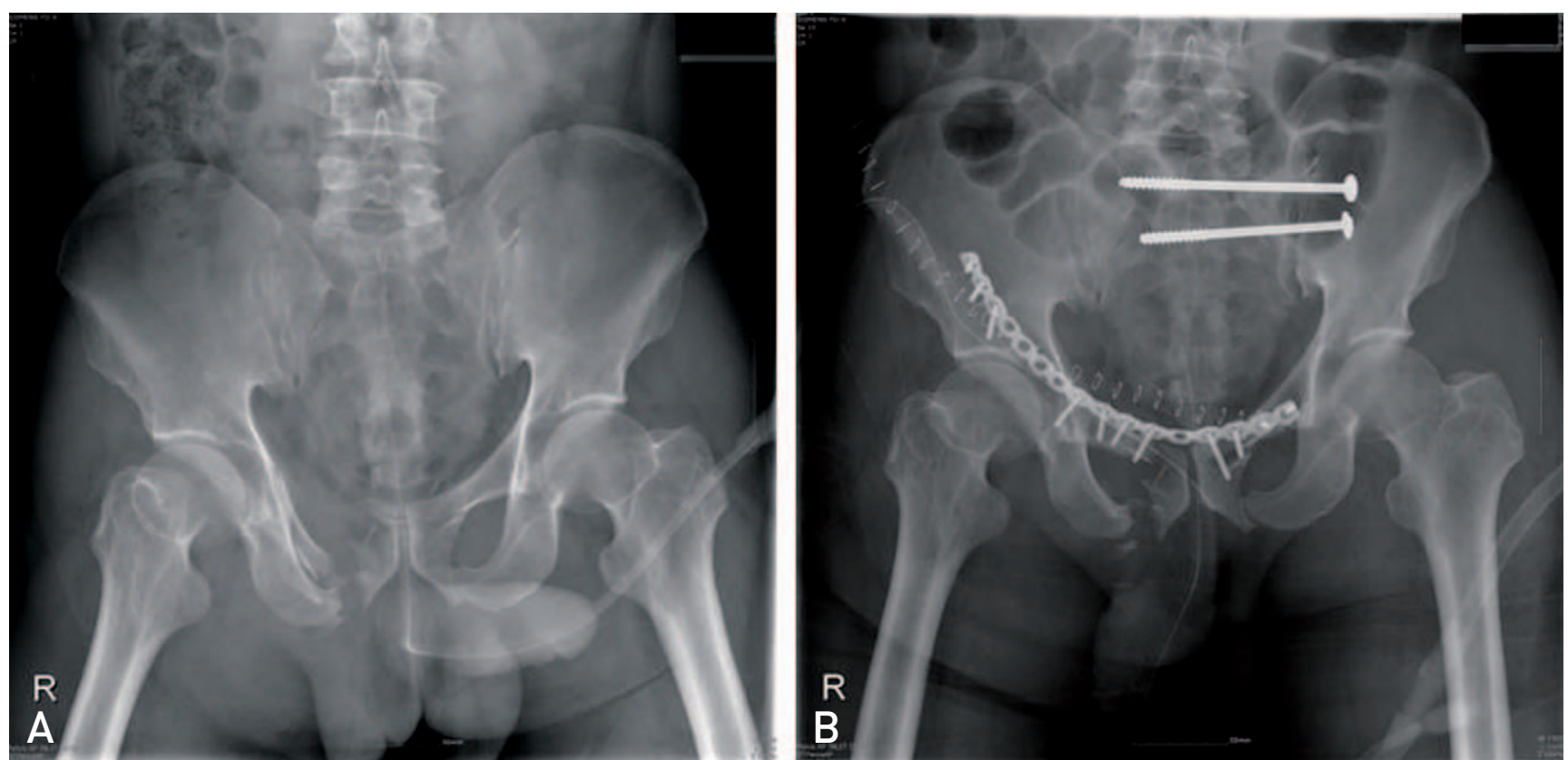

Fig. 4. Preoperative $(A)$ and postoperative $(B)$ radiographs show rigid fixation of the pelvic ring by anterior plating with an ilioinguinal approach and percutaneous iliosacral screws on S1and 2. 
In type $\mathrm{C}$ injuries, dislocated sacroiliac joints require reduction and internal fixation (in addition to the use of external fixators) to reconstruct the posterior structures important for pelvic ring stability ${ }^{18}$. A surgeon needs to carefully follow appropriate clinical guidelines by identifying the advantages and disadvantages of surgical methods after thoroughly examining the patient's condition.

The techniques for the insertion of external fixators are divided into anterosuperior and anteroinferior according to the screw fixation method. In the anterosuperior technique, the screws are inserted from the anterior iliac crest $^{1,23,24)}$. In the anteroinferior technique, they are inserted from the upper part of the anteroinferior iliac spine to the dense bone in the upper part of the acetabulum ${ }^{5}$. In the former method, early insertion is easy, but reliable firm internal fixation is difficult because of the curved shape of the iliac wing and its paper-thin middle part. Moreover, the stiffness of the sacroiliac joints with external fixators during exercise is unfavorable in comparison with the results of the latter method $(163 \mathrm{~N} / \mathrm{mm}: 203 \mathrm{~N} / \mathrm{mm})^{4}$. Therefore, the anteroinferior techniques is more commonly used ${ }^{45,25}$. A recent study reported that sufficient fixation ability can be achieved by placing a single screw from the anteroinferior direction on each side in patients with type B injuries ${ }^{26}$.

\section{REFERENCES}

1.Brown TD, Stone JP, Schuster JH, Mears DC. External fixation of unstable pelvic ring fractures: comparative rigidity of some current frame configurations. Med Biol Eng Comput. 1982;20:727-33.

2. Failinger MS, McGanity PL. Unstable fractures of the pelvic ring. J Bone Joint Surg Am. 1992;74:781-91.

3. Kim SJ, Chung HK, Lee KH, Chung ST. A clinical study of the pelvic bone fracture. J Korean Orthop Assoc. 1991; 26:1441-9.

4. Kim WY, Hearn TC, Seleem O, Mahalingam E, Stephen D, Tile M. Effect of pin location on stability of pelvic external fixation. Clin Orthop Relat Res. 1999;361:237-44.

5. Kim WY, Ji JH, Kim YY, Yang YJ, Lee DY. Anterior fixation techniques on unstable pelvic ring injury. J Korean Orthop Assoc. 2005:40:8-13.

6. Pennal GF, Tile M, Waddell JP, Garside H. Pelvic disruption: assessment and classification. Clin Orthop Relat Res. 1980;151:12-21.

7. Bosch U, Pohlemann T, Tscherne H. Primary management of pelvic injuries. Orthopade. 1992;21:385-92.

8. Routt ML Jr, Simonian PT, Ballmer F. A rational approach to pelvic trauma. Resuscitation and early definitive stabilization. Clin Orthop Relat Res. 1995;318: 61-74.

9. Goldstein A, Phillips T, Sclafani SJ, et al. Early open reduction and internal fixation of the disrupted pelvic ring. J Trauma. 1986;26:325-33.

10. Tile M, Pennal GF. Pelvic disruption: principles of management. Clin Orthop Relat Res. 1980;151:56-64.

11. Tile M. Pelvic ring fractures: should they be fixed? J Bone Joint Surg Br. 1988;70:1-12.

12. Copeland CE, Bosse MJ, McCarthy ML, et al. Effect of trauma and pelvic fracture on female genitourinary, sexual, and reproductive function. J Orthop Trauma. 1997;11:73-81.

13. Johnson KD, Cadambi A, Seibert GB. Incidence of adult respiratory distress syndrome in patients with multiple musculoskeletal injuries: effect of early operative stabilization of fractures. J Trauma. 1985;25:375-84.

14. Peltier LF. Complications associated with fractures of the pelvis. J Bone Joint Surg Am. 1965;47:1060-9.

15. van Gulik TM, Raaymakers EL, Broekhuizen AH, Karthaus AJ. Complications and late therapeutic results of conservatively managed, unstable pelvic ring disruptions. Neth J Surg. 1987;39:175-8.

16. Young JW, Burgess AR, Brumback RJ, Poka A. Pelvic fractures: value of plain radiography in early assessment and management. Radiology. 1986;160:445-51.

17. Bucholz RW. Pathomechanics of pelvic ring disruptions. Instr Course Lect. 1987;10:167-9.

18. Mears DC, Capito CP, Deleeuw H. Posterior pelvic disruptions managed by the use of the Double Cobra Plate. Instr Course Lect. 1988;37:143-50.

19. Matta JM, Saucedo T. Internal fixation of pelvic ring fractures. Clin Orthop Relat Res. 1989;242:83-97.

20. Routt ML Jr, Simonian PT, Agnew SG, Mann FA. Radiographic recognition of the sacral alar slope for optimal placement of iliosacral screws: a cadaveric and clinical study. J Orthop Trauma. 1996;10:171-7.

21. Gras F, Marintschev I, Klos K, Mückley T, Hofmann GO, Kahler DM. Screw placement for acetabular fractures: which navigation modality (2-dimensional vs. 3dimensional) should be used? An experimental study. J Orthop Trauma. 2012;26:466-73.

22. Mears DC, Fu FH. Modern concepts of external skeletal fixation of the pelvis. Clin Orthop Relat Res. 1980;151:65-72.

23. Lee S, Bae SU, Jung WK, Kim CH, Kim JH. Treatment of the unstable pelvic fracture by external skeletal fixation. $J$ Korean Orthop Assoc. 1992;27:1818-26.

24. Slätis P, Karaharju EO. External fixation of unstable pelvic fractures: experiences in 22 patients treated with a trapezoid compression frame. Clin Orthop Relat Res. 1980;151:73-80.

25. Liu J, Lai KA, Chou YL. Strength of the pin-bone interface of external fixation pins in the iliac crest. A biomechanical study. Clin Orthop Relat Res. 1995;310:237-44.

26. Gänsslen A, Hildebrand F, Kretek C. Supraacetabular external fixation for pain control in geriatric type B pelvic injuries. Acta Chir Orthop Traumatol Cech. 2013;80:101-5. 